\title{
Pharmacological and Biochemical Assessment of SM-10888, a Novel Cholinesterase Inhibitor
}

\author{
Kazuichi NATORI, Yuko OKAZAKI, Tsunemasa IRIE \\ and Junki KATSUBE \\ Research Laboratories, Sumitomo Pharmaceuticals Co., Ltd., \\ 1-98. Kasugadenaka 3-chome. Konohana-ku. Osaka 554, Japan \\ Accepted February 7, 1990
}

\begin{abstract}
The effects of the compound SM-10888 (9-amino-8-fluoro-1,2,3,4,tetrahydro-2,4-methanoacridine citrate) in a number of pharmacological and biochemical tests were studied and compared to those of tacrine (THA), amiridin. HP-029 and physostigmine. SM-10888 inhibited cholinesterase activity (IC50: $\left.2.3 \times 10^{-7} \mathrm{M}\right)$ in rat cortical $P_{2}$ fraction with almost the same potency as THA, while SM-10888 was 2-4 times more potent than amiridin and HP-029, but about 10 times less potent than physostigmine. When given to mice p.o., SM-10888 induced central (hypothermia) and peripheral (salivation) cholinergic effects. When the ratio of the ED50 value for hypothermia to that for salivation was regarded as the index of the selectivity to the central nervous system (CNS). SM-10888 was shown to be about 3 times more selective to the CNS than the other four drugs in mice. The minimum effective dose of SM-10888 for its increasing effect on acetylcholine $(\mathrm{ACh}$ ) content in the mouse cerebral cortex was about 10 times higher than that of physostigmine, but 5-10 times lower than those of THA, amiridin and HP029. These results suggest that SM-10888 is an adequate drug for increasing the brain ACh content with less peripheral cholinergic side effects than THA, amiridin, HP-029 and physostigmine.
\end{abstract}

It was reported that a specific deficit was observed in choline acetyltransferase in the neocortex and hippocampus from patients with senile dementia of the Alzheimer type (SDAT) (1-5). This enzyme is responsible for the formation of acetylcholine (ACh) from choline and acetyl-coenzyme A. Moreover, various types of evidence have indicated that cholinergic function is involved in memory and learning in humans as well as animals (6-8). These observations encouraged clinical trials with cholinesterase (ChE) inhibitors such as physostigmine $(9,10)$.

In 1986. Summers et al. (11) reported that oral administration of tacrine (THA) significantly improved the symptoms including memory deficit of SDAT. Since THA is wellknown to be a potent centrally acting ChE inhibitor (12, 13), the positive response of SDAT to THA not only supported the cholinergic hypothesis but encouraged the in- vestigation of a palliative treatment of SDAT. However, on the other hand. Summers reported that THA induced peripheral cholinergic side effects such as excessive micturition, diarrhea and diaphoresis (11). Moreover, THA was reported to be mutagenic in the Ames test (14).

SM-10888 (9 - amino - 8 - fluoro-1,2,3,4 tetrahydro-2.4-methanoacridine citrate) is the THA derivative which was selected from many THA derivatives in view of its selective action on the central nervous system (CNS). The chemical structure of SM-10888 is shown in Fig. 1. In this paper, we report the effects of SM-10888 in several pharmacological and biochemical tests in comparison with those of THA; two THA derivatives: amiridin $(15,16)$ and HP-O29 $(17,18)$, and physostigmine.

\section{Materials and Methods}

Materials: SM-10888, amiridin (NIK-247) 
SM-10888<smiles>[Y10][C@H]1C[C@H]2Cc3c(nc4cccc(F)c4c3N)[C@H]1C2</smiles>

THA<smiles>Nc1c2c(nc3ccccc13)CC[C@H](Cl)C2</smiles>

Amiridin<smiles>Nc1c2c(nc3c1CC[C@H](Cl)C3)CCC2</smiles>

HP- 029<smiles>Nc1c2c(nc3ccccc13)CCC(=CC(=O)C(=O)O)CC2O</smiles>

Fig. 1. Chemical structures of SM-10888. THA, amiridin and HP-029

and HP-029 were synthesized in our laboratories. THA (hydrochloride) and physostigmine (sulfate) were purchased from Aldrich Chemical Co., Inc. and Wako Pure Chemical Industries, Ltd., respectively. DNA (calf thymus) was obtained from Worthington Biochemical Corporation. New Jersey. Other drugs and reagents were obtained from commercial sources and the highest quality available was used.

Animals: Four-week old male ddY mice and six-week male S.D. rats were purchased from the Shizuoka Agricultural Cooperative Association for Laboratory Animals (Hamamatsu, Japan) and used after acclimation for 1 week under free access to food and water.

Drugs: Drugs were dissolved in physiological saline for oral (p.o.) and intraperitoneal (i.p.) administration.

Inhibitory effect on ChE activity (in vitro): The cortical $P_{2}$ fraction was prepared as described by Shoemaker and Nickolson (19) from the rat brain. The $P_{2}$ fraction was gently suspended in 40 volumes of $0.1 \mathrm{M}$ phosphate buffer ( $\mathrm{pH}$ 7.4) and used as the enzyme source. ChE activity was determined essentially by the method of Ellman et al. (20). The total volume for each assay was $2.5 \mathrm{ml}$ consisting of the enzyme (50 $/ \mathrm{g}$ protein). $10 \mu$ of dimethylsulfoxide (DMSO) solution of each test compound and $0.3 \mu \mathrm{mol} 5,5^{\prime}$ dithiobis(2-nitrobenzoic acid). The control samples received $10 \mu \mathrm{l}$ of DMSO alone. The mixture was incubated at $37^{\circ} \mathrm{C}$ for $5 \mathrm{~min}$ before the addition of the substrate $(0.5 \mu \mathrm{mol}$ of acetylthiocholine) to start the reaction. Then the incubation mixtures were further incubated for $10 \mathrm{~min}$ at $37^{\circ} \mathrm{C}$, and the reaction was stopped by the addition of $0.5 \mathrm{ml}$ of acetone. ChE activity was determined by measuring the optical density at $412 \mathrm{~nm}$ against a blank. The concentration of drug at which $50 \%$ of the control ChE activity was inhibited (IC50) was calculated graphically.

Hypothermia: As described by Palacios et al. (21). the rectal temperature of the mouse was measured by a thermoprobe inserted into the rectum. The temperature was measured before and at 15, 30,60, 90 and 120 min after the drug application. The differences between the post- and pretreatment temperature were calculated and the maximal hypothermia response was used as a measure of the drug effect. The dose that produced $50 \%$ of the maximal effect (ED50) was calculated graphically.

Salivation: Salivation was observed and scored essentially by the method of Rathbun and Slater (22) at 15, 30,60,90 and $120 \mathrm{~min}$ after the drug administration. The signs were scored as follows: 0 , if salivation did not exceed that of normal mice: 1 . if saliva was obvious around the teeth: 2 , if saliva wet a narrow band around the mouth or if saliva wet the area under the jaw: and 3 , if saliva was dripping from the mouth. The sum of the scores in each mouse was used as a measure of the drug effect. ED50 was calculated graphically as in the case with hypothermia.

ACh determination in the mouse cerebral cortex: Drugs were administered p.o. to mice, and the animals were killed 30 min later by using microwave irradiation focused on the head (2 kW for $0.6 \mathrm{sec}$ ) (Nakagawa, NJE2601). Then the brain was removed and the cerebral cortex was separated. ACh was extracted according to the method described by Ikarashi et al. (23). ACh content was determined by high-performance liquid chromatography according to the method described by Ajima and Kato (24). 
Binding to nucleic acid: The amount of the drug binding to DNA was determined by the equilibrium dialysis method described by Peacocke and Skerrett (25).

Statistical analysis: Statistical differences were evaluated using Dunnett's $t$-test. $P$ values less than 0.05 were considered significant.

\section{Results}

Effect on ChE activity: Inhibitory effects of SM-10888. THA, amiridin, HP-029 and physostigmine on ChE activity are shown in Fig. 2. Control ChE activity was $60.3 \mathrm{nmol} /$ $\mathrm{mg}$ protein/min (the mean of duplicate assays). SM-10888 (IC50: $2.3 \times 10^{-7} \mathrm{M}$ ) inhibited ChE activity with almost the same potency as THA (IC50: $\left.1.9 \times 10^{-7} \mathrm{M}\right)$. SM10888 was about 2 and 3.5 times more potent than amiridin (IC50:5.0 $\left.510^{-7} \mathrm{M}\right)$ and $\mathrm{HP}$ 029 (IC50: $7.9 \times 10^{-7} \mathrm{M}$ ), respectively. Physostigmine (IC50: $1.6 \times 10^{-8} \mathrm{M}$ ) was about 10 times more potent than SM-10888. The kinetic data with SM-10888 concentrations of 0 (control). $10^{-7}$ and $3 \times 10^{-7} \mathrm{M}$ were plotted according to Lineweaver-Burk (Fig. 3). The apparent $K_{m}$ values were 0.11 . 0.20 and $0.28 \mathrm{mM}$, and the apparent $V_{\max }$ values were $77.5,73.8$ and $54.6 \mathrm{nmol} / \mathrm{mg}$ protein $/ \mathrm{min}$ at $0,10^{-7}$ and $3 \times 10^{-7} \mathrm{M}$, respectively. SM-10888 was shown to inhibit ChE activity in a competitive manner at $10^{-7}$ $\mathrm{M}$. while it did in a manner which included not

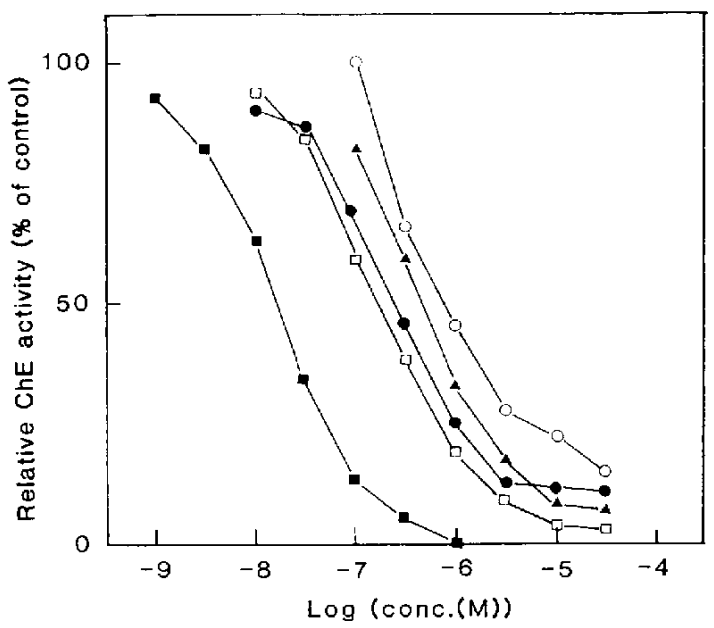

Fig. 2. Concentration-dependent effects of SM10888. THA, amiridin. HP-O29 and physostigmine on the ChE activity in the $P_{2}$ fraction of rat cerebral cortex. Each value is the mean of duplicate assays. SM-10888, O: THA. $\square$; amiridin, A: HP-029, O: physostigmine $\square$

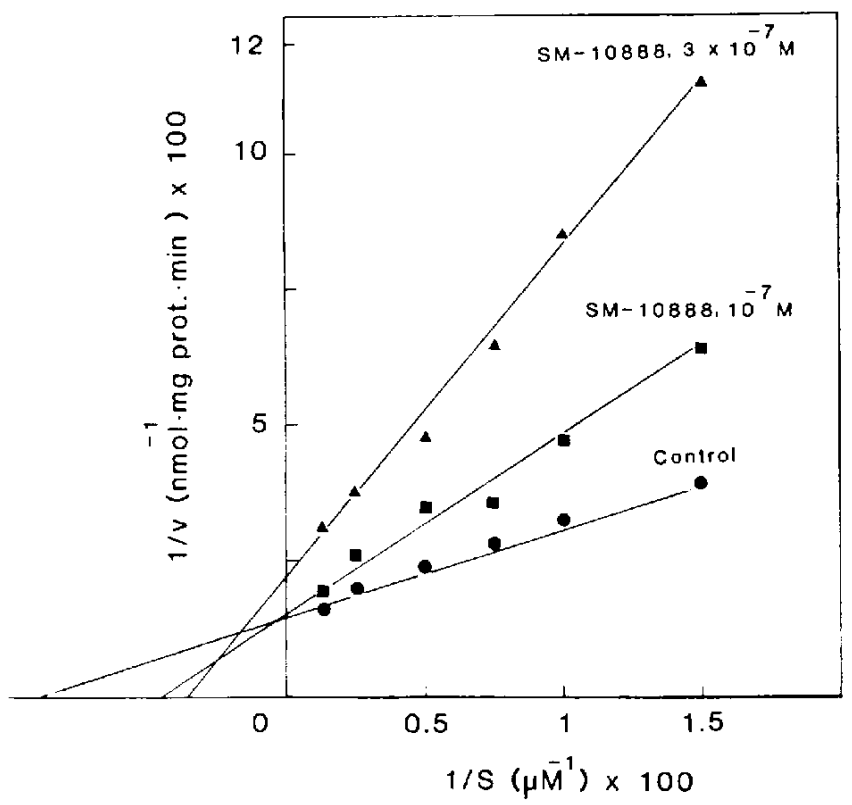

Fig. 3. Lineweaver-Burk plot of inhibition of ChE activity in the $P_{2}$ fraction of rat cerebral cortex by SM-10888. 
only a competitive component but also a noncompetitive component at $3 \times 10^{-7} \mathrm{M}$.

Central cholinergic effect (hypothermia) in mice: The time-dependency of hypothermia is shown in Fig. 4 in the cases of SM-10888 and THA. Hypothermia induced by SM10888 administered p.o. to mice reached the maximum 30 or 60 min after the administra- tion. The duration was dose-dependent. In the case of THA, hypothermia reached the maximum 30 or 60 min after the administration, and the duration was dose dependent as in the case with SM-10888. Hypothermia induced by $S M-10888$ at $20 \mathrm{mg} / \mathrm{kg}$, p.o., was antagonized $15 \mathrm{~min}$ prior to i.p.-administration of atropine sulfate (a centrally and peri-
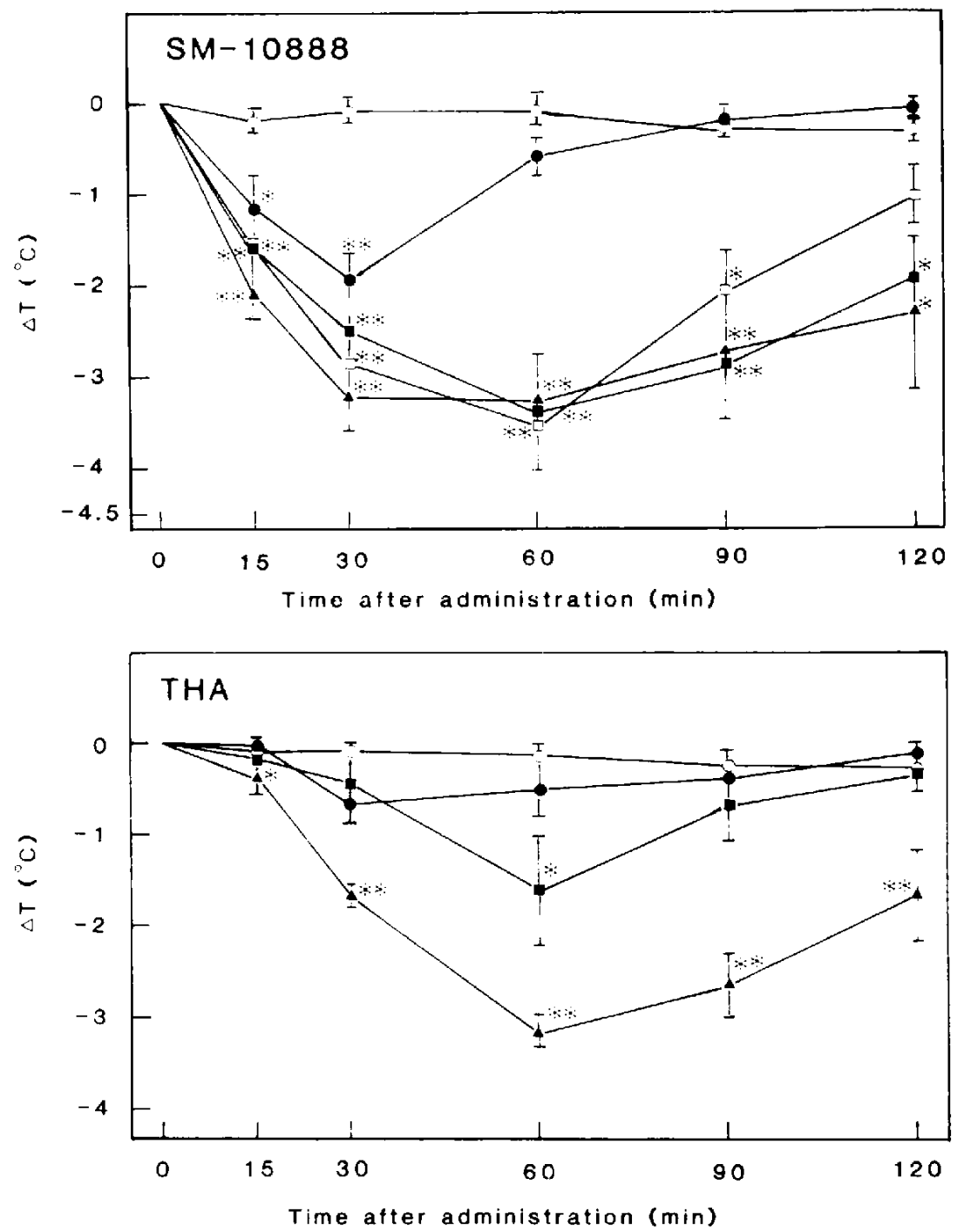

Fig. 4. Time-response curves for the effects of various doses of SM-10888 (upper panel) and THA (lower panel) on body temperature in mice. Drugs were administered p.o. to mice, and the rectal temperature was measured. $\Delta T$ is the difference between post- and pretreatment temperature. Symbols are. for the upper panel: O. control (saline): , 10: $\square .20: \square, 30$ and A. $40 \mathrm{mg} / \mathrm{kg}$ of SM-10888. Lower panel: $O$. control (saline);, $20 ; \square, 30$ and $\mathbf{A}, 40 \mathrm{mg} / \mathrm{kg}$ of THA. Points are means $\pm S . E .(n=4$ or 5$)$. ${ }^{*} \mathrm{P}-0.05$ and **P.0.01 vs. control (Dunnett's $t$-test). 
pherally acting muscarinic antagonist) in a dose-dependent manner, but the antagonism by methylatropine bromide (a peripherally acting muscarinic antagonist) was weak even at a high dose (Fig. 5). Almost the same result (data not shown) was obtained in the case of hypothermia elicited by THA at $40 \mathrm{mg} / \mathrm{kg}$. P.o.

Peripheral cholinergic effect (salivation) in mice: Time-dependency in the score of salivation induced by SM-10888 and THA. p.o., is shown in Fig. 6. Salivation induced by SM-10888 reached the maximum 15,30 and 60 min after the administration in the cases of 20.30 and $40 \mathrm{mg} / \mathrm{kg}$. p.o., respectively. When THA was administered p.o., salivation reached the maximum 30 min after the administration. In both these cases, salivation disappeared at least $120 \mathrm{~min}$ after the administration. Salivation induced by $S M-1088820 \mathrm{mg} / \mathrm{kg}$, p.o.. as distinct from hypothermia, was blocked by either atropine sulfate or methylatropine bromide i.p. at a low dose (Fig. 5). The same result (data not shown) was obtained in the case of salivation induced by THA at $40 \mathrm{mg} /$ kg. p.o.

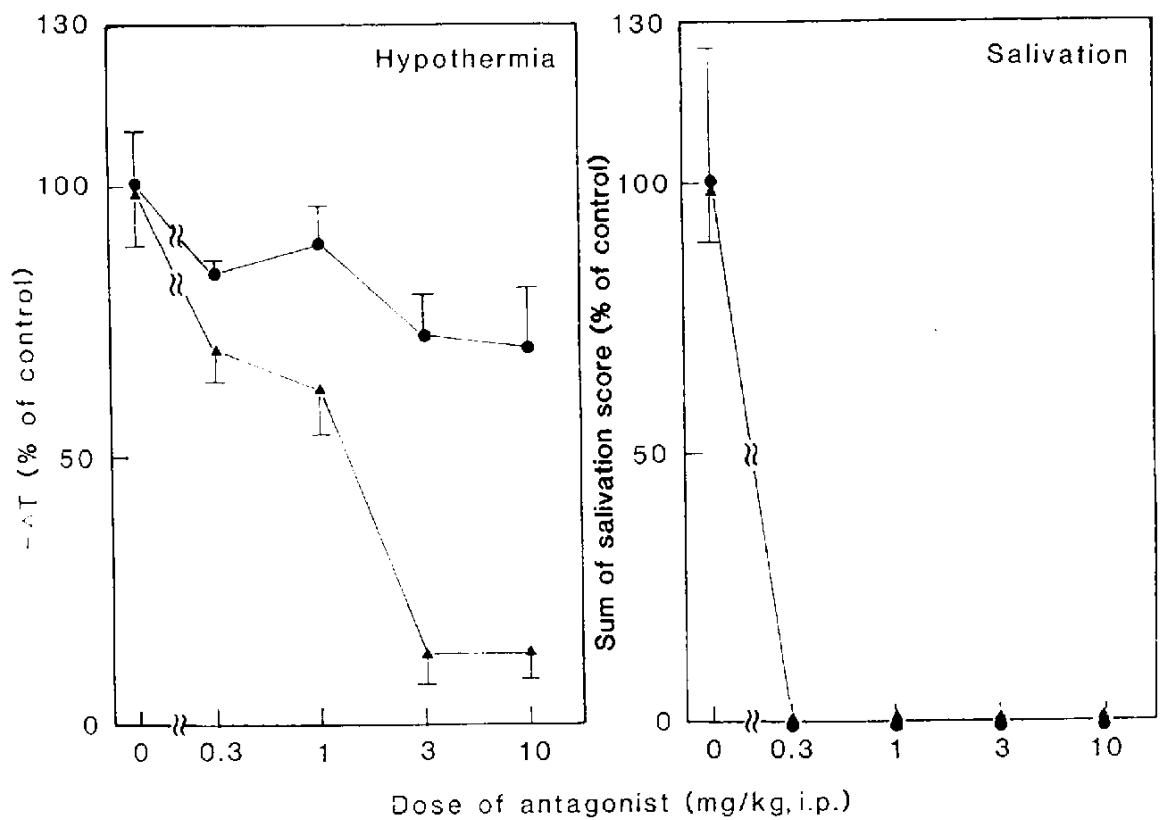

Fig. 5. Effects of pretreatment with atropine sulfate or methylatropine bromide on hypothermia (left panel) and salivation (right panel) elicited by $S M-10888$ at $20 \mathrm{mg} / \mathrm{kg}$, p.o., in mice. Antagonists were administered i.p. 15 min before SM-10888 administration. $1 \mathrm{~T}$ is the maximum hypothermia within $2 \mathrm{hr}$. - SM-10888 plus methylatropine bromide: $\boldsymbol{A}, \mathrm{SM}-10888$ plus atropine sulfate. Points are means S.E. $(n=4$ or 5$)$.

Selectivity of the action to CNS in mice: Dose-response relationships for hypothermia and salivation induced by SM-10888 or THA p.0. are shown in Fig. 7. In either case with SM-10888 or THA, the maximum dose given to mice was fixed at $40 \mathrm{mg} / \mathrm{kg}$, p.o., because doses above $40 \mathrm{mg} / \mathrm{kg}$. p.o., were lethal in mice. The maximum hypothermia were $-3.6 \pm$ $0.4^{\circ} \mathrm{C}$ and $-3.3 \pm 0.2^{\circ} \mathrm{C}$ (mean \pm S.E., $n=5$ ) in the cases of SM-10888 and THA, respectively. The maximum values of the sum of salivation score were $5.2 \pm 0.5$ and $3.8 \pm 0.4$ (mean \pm S.E., $n=5$ ) in the cases of SM-10888 and THA, respectively. Calculated ED50 values of SM-10888, THA, amiridin, HP-029 and physostigmine are summarized in Table 1. With respect to hypothermia, ED50 value of SM-10888 was about 8 times higher than that of physostigmine, but 3-10 times lower than those of THA, amiridin and HP-029. In the case of salivation. ED50 value of SM10888 was about 20 times higher than that of physostigmine and 3 times lower than that of HP-029 but comparable with THA and amiridin. As the index of the selectivity to 

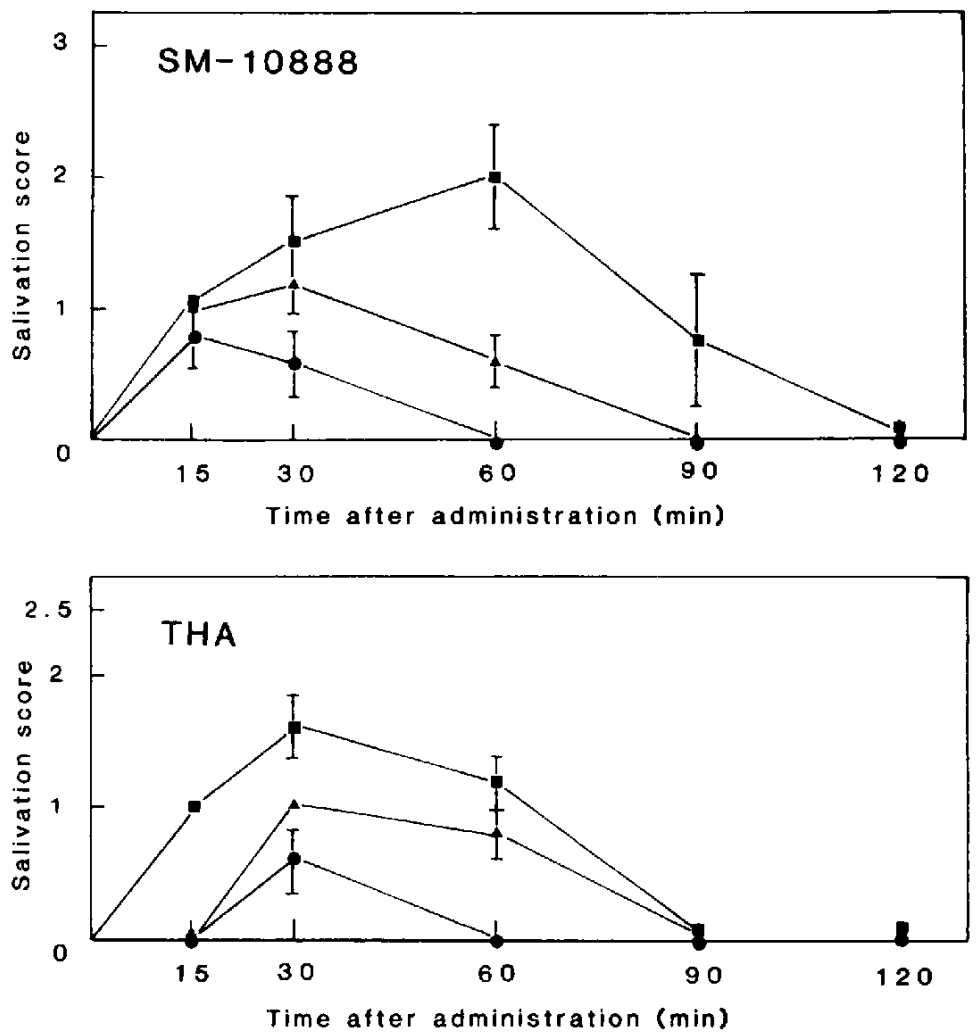

Fig. 6. Time-response curves for the effects of various doses of SM-10888 (upper panel) and THA (lower panel) on salivation in mice. Drugs were administered p.o. to mice and salivation induced was scored as described in the Methods. Symbols are, for either upper or lower panel: $-20 ; \boldsymbol{\Lambda}, 30$ and $40 \mathrm{mg} / \mathrm{kg}$ of SM-10888 or THA. Points are means \pm S.E. $(n=4$ or 5$)$.

Table 1. ED50 values for central (hypothermia) and peripheral (salivation) effects of the p.o. administration of SM-10888 and other ChE inhibitors in mice

\begin{tabular}{lccc}
\hline Compound & Hypothermia & Salivation & Hypothermia/Salivation \\
SM-10888 & -.7 & 29.8 & 0.29 \\
THA & 29.0 & 31.8 & 0.91 \\
Amiridin & 35.8 & 36.2 & 0.99 \\
HP-029 & 108.1 & 99.9 & 1.08 \\
Physostigmine & 1.1 & 1.4 & 0.81 \\
\hline
\end{tabular}

Values represent ED50s in $\mathrm{mg} / \mathrm{kg}$, p.o. and were obtained graphically from the dose-response curves with at least 4 doses and 4 or 5 mice/dose.

CNS, the ratio of ED50 value for hypothermia to that for salivation in each drug is also shown in Table 1. According to this index, it was shown that the action of SM-10888 was about 3 times more selective to CNS than THA, amiridin. HP-029 and physostigmine in mice.

Effect on ACh content in the mouse cerebral cortex: In our preliminary experiments, it was shown that the increase of $\mathrm{ACh}$ content in the mouse cerebral cortex induced by SM-10888 (10 and $20 \mathrm{mg} / \mathrm{kg}$ ). THA (30 $\mathrm{mg} / \mathrm{kg}$ ), amiridin $(40 \mathrm{mg} / \mathrm{kg})$. HP-029 (60 $\mathrm{mg} / \mathrm{kg})$ and physostigmine $(0.5 \mathrm{mg} / \mathrm{kg})$ reached the maximum around $30 \mathrm{~min}$ after the oral administration (data not shown). 


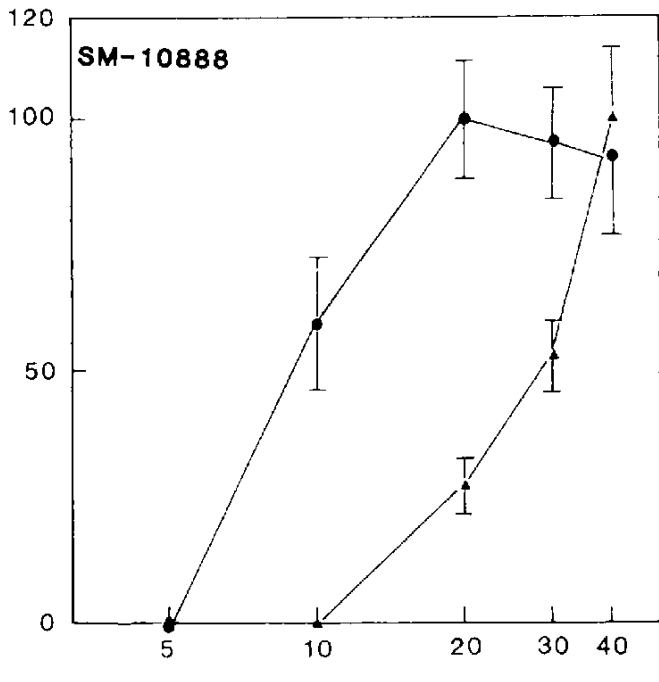

SM-10888 (mg/kg,p.o.)

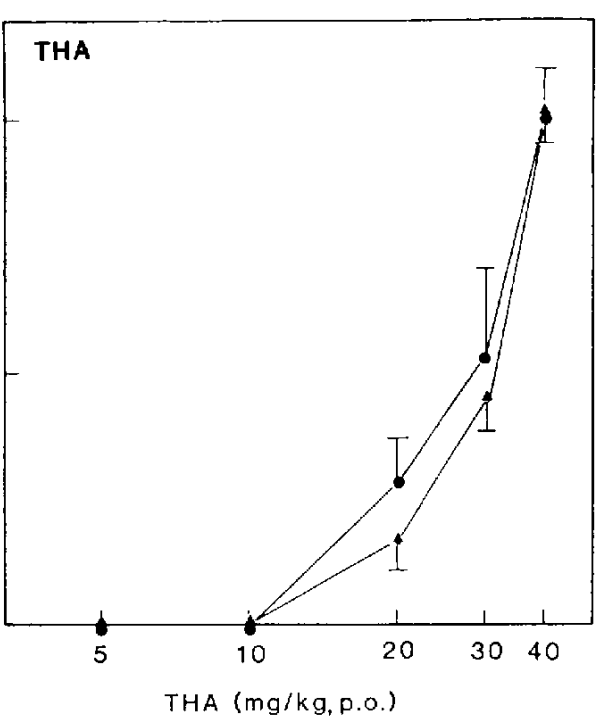

THA (mg/kg, p.o.)

Fig. 7. Dose-response relationships for hypothermia and salivation elicited by p.o. administration of SM-10888 (left panel) and THA (right panel) to mice. $\Delta \mathrm{T}$ is the maximum response within $2 \mathrm{hr}$ at that dose level. O. Hypothermia; $\mathbf{A}$. salivation. Points are percents of the maximum (means \pm S.E., $n=4$ or $5)$.

Table 2. Minimum effective doses of SM-10888 and other ChE inhibitors causing significant increase of ACh content in the mouse cerebral cortex when administered p.o. to mice

Compound

SM-10888

THA

Amiridin

HP-029

Physostigmine
Minimum effective dose (mg/kg, p.o.)

6

$(3,6,10,15$ and 20)

30

$(5,10,15,20$ and 30$)$

40

$(10,20,30,40$ and 60$)$

60

$(20,40,60,100$ and 120$)$

0.5

$(0.1,0.25,0.5,1$ and 2$)$

Drugs were given p.o. to 5 mice/each dose 30 min before microwave irradiation. Minimum effective dose was defined as the minimum dose among the doses administered p.o. that caused a significant (Dunnett's $t$-test. $\mathrm{P}<0.05$ vs. control) increase of $\mathrm{A} . \mathrm{Ch}$ content in the mouse cerebral cortex. The values in parentheses indicate the tested doses $(\mathrm{mg} / \mathrm{kg}$, p.o.).

Therefore, in order to compare the effect of SM-10888 p.o. On ACh content to those of THA amiridin. HP-029 and physostigmine, ACh content in the mouse cerebral cortex was determined $30 \mathrm{~min}$ after the administration. Dose-response relationships for the effects of SM-10888 and THA p.o. on ACh content in the mouse cerebral cortex are shown in Fig.
8. The minimum doses among the tested doses for a significant increase of $\mathrm{ACh}$ content in the cerebral cortex [ED $\min (A C h)]$ were $6 \mathrm{mg} / \mathrm{kg}$, p.o., and $30 \mathrm{mg} / \mathrm{kg}$, p.o., in the cases of SM-10888 and THA, respectively. The ED ${ }_{\min }$ (ACh) of SM-10888 and the related drugs are summarized in Table 2. The $\mathrm{ED}_{\min }(\mathrm{ACh})$ of SM-10888 was 5-10 times 


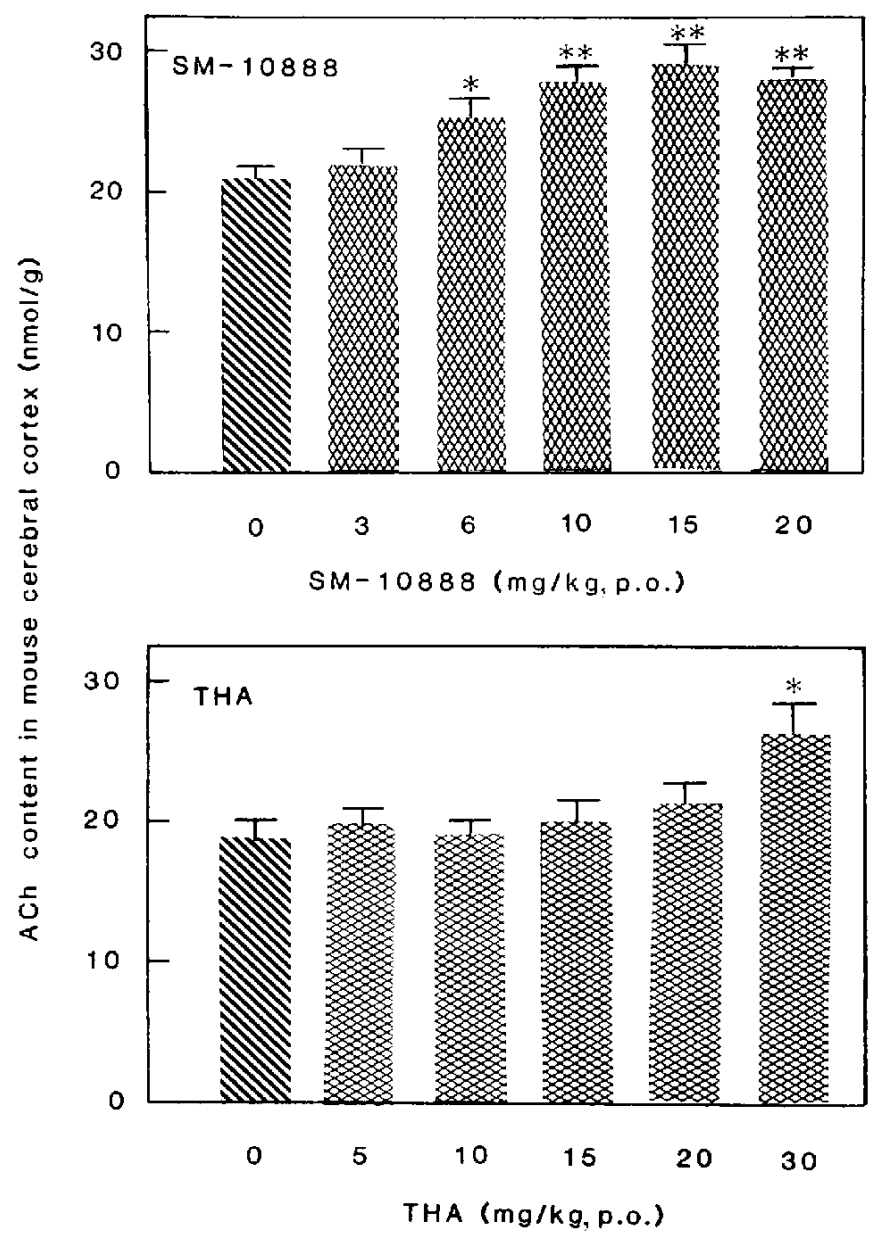

Fig. 8. Dose-dependent effect of SM-10888 (upper panel) and THA (lower panel) on ACh content in mouse cerebral cortex. Drugs were administered p.o. to mice $30 \mathrm{~min}$ before killing the animals by microwave irradiation, Values are expressed as the means \pm S.E. $(n=5), \quad P<0.05$ and ${ }^{* *} P<0.01$ vs. control (Dunnett's $t$-test).

lower than those of THA and two THA derivatives, but about 10 times higher than physostigmine.

Binding to DNA: The concentration-dependency of the amount of SM-10888 or THA binding to $3 \mathrm{mM}$ (as nucleotide) of DNA is shown in Fig. 9. The amount of SM-10888 binding to DNA was saturated at about $3 \mathrm{mM}$ of SM-10888 while that of THA was not at above $3 \mathrm{mM}$ of THA. The amount of SM10888 binding to DNA was about 3 times less than that of THA at above $0.1 \mathrm{mM}$.

\section{Discussion}

The kinetic data (Fig. 3) suggest that at the low concentration of SM-10888, ChE activity is inhibited in a competitive manner. On the other hand, it is suggested that at the high concentration of SM-10888, ChE activity is inhibited in a manner including a noncompetitive component as well as a competitive one. According to the increase of SM10888 concentration. SM-10888 may bind to the enzyme not only at the substrate binding site but also at site other than the substrate binding site. In order to study whether SM10888 is a reversible ChE inhibitor as was reported for THA (26), a dialysis experiment is now in progress.

It is well-known that tremorine, a centrally 


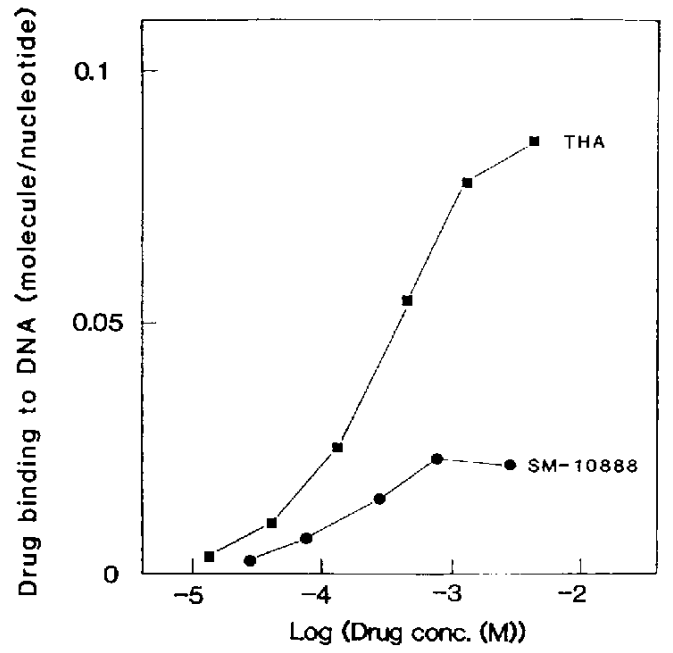

Fig. 9. Concentration-dependent effect of SM10888 or THA on the amount of each drug binding to DNA. Amount of the drug binding to DNA was determined by the equilibrium dialysis method. The concentration of DNA was $3 \mathrm{mM}$ as nucleotide.

acting muscarinic agonist, induces hypothermia in mice; and this hypothermia is a central cholinergic symptom, since this symptom is antagonized by the centrally acting muscarinic antagonists, but is not antagonized by the peripherally acting ones (27). Hypothermia induced by SM-10888 administered p.o. to mice was antagonized by prior atropine sulfate (a centrally and peripherally acting muscarinic antagonist) administration in a dose-dependent manner, while antagonism by methylatropine bromide (a peripherally acting muscarinic antagonist) was weak even at a high dose (Fig. 5). These results showed that hypothermia induced by SM-10888 given p.o. to mice was a central cholinergic symptom as is the case with tremorine. As our results indicate, the administration of SM10888 induced a dose-dependent increase of ACh content in the mouse cerebral cortex (Fig. 8). These results suggest that the administration of SM-10888 to mice induces hypothermia by increasing ACh concentration in the CNS synaptic cleft through an inhibitory effect on acetylcholinesterase activity.

It is well-known that salivation induced by muscarinic agonists in mice is a peripheral cholinergic symptom (21). Salivation induced by SM-10888 to mice was blocked by either atropine sulfate or methylatropine bromide (Fig. 5). Moreover, it was shown that salivation was not induced by the intracerebroventricular administration of SM-10888 to mice (1-100 $\mu \mathrm{g} /$ mouse) (data not shown). These results showed that salivation induced by SM10888 given p.o. to mice was a peripheral cholinergic symptom.

Although the IC50 value for the inhibitory effect of SM-10888 on ChE activity was slightly higher than that of THA (Fig. 2), the ED50 value for the hypothermic effect of SM10888 was shown to be about 3 times lower than that of THA (Table 1). In the case of THA, amiridin. HP-O29 and physostigmine, the order of $1 \mathrm{C} 50$ values for their inhibitory effect on ChE activity is the same as that of the ED50 values for the hypothermic effect. Moreover, the ED50 values for the hypothermic effect of THA, amiridin, HP-O29 and physostigmine were comparable with those for the salivant effects of these compounds (Table 1). On the other hand, the ED50 value for the hypothermic effect of SM-10888 was about 3 times lower than that for the salivant effect of SM-10888 (Table 1). These observations suggest that the action of SM10888 is about 3 times more selective to the CNS than THA, amiridin, HP-029 and physostigmine in mice. Lipophilicity of SM-10888 $\left(\log P^{*}: 2.2\right.$, octanol-1/15 M phosphate buffer, $\mathrm{pH}$ 7.4) was shown to be much higher than that of THA $\left(\log P^{*}:-0.13\right)(T$. Nakajima, unpublished data). Therefore, the higher selectivity of SM-10888 to the CNS as compared with that of THA may be partly interpreted as being due to the much higher lipophilicity of SM-10888 compared to THA and hence its better penetration through the blood-brain barrier. To discuss the relationship between the selectivity to the CNS and the lipophilicity precisely, we are now determining the $\log P^{*}$ values of amiridin, HP-029 and physostigmine.

Moreover, there is a significant correlation $(r=0.92, P<0.05)$ between $E D_{\min }(A C h)$ and ED50 values for the hypothermic effect of SM-10888, THA, amiridin, HP-029 and physostigmine (Tables 1 and 2). This observation suggests that the hypothermic effect of these ChE inhibitors is due to the increasing 
effect of these drugs on the brain ACh content in mice. The $E D_{\min }$ (ACh) of SM-10888 was the lowest of the four THA-related drugs (Table 2). For example, the $\mathrm{ED}_{\mathrm{mIn}}(\mathrm{ACh})$ of SM-10888 was 5 times lower than that of THA (Fig. 8). This finding supports that the action of $S M-10888$ is about 3 times more selective to the CNS than that of THA as discussed above.

The number of THA molecules binding to DNA was about 3 times more than SM-10888 at above $0.1 \mathrm{mM}$ (Fig. 9). Recently, we were informed that THA exhibited mutagenic activity against tester strain TA-1537 in the Salmonella typhimurium incorporation assay. while SM-10888 did not exhibit any under the same condition ( $\mathrm{S}$. Kogiso, unpublished data). This finding supports the result reported by Townsend and Sehgel (14) that THA exhibited mutagenic activity against tester strain TA-97a in the Salmonella typhimurium incorporation assay. In view of the fact that the chemical structure of THA is more planar than that of SM-10888, it is supposed that the THA molecules are inserted into and intercalated into DNA more easily than SM-10888. Therefore, our results may support the hypothesis that THA, as distinct from SM-10888, exerts mutagenicity in the Ames test due to its considerably higher binding to DNA as compared to the binding of SM-10888.

In summary, if the centrally acting ChE in hibitor THA is useful for the therapy of patients with SDAT as was reported by Summers et al. (11), SM-10888 should be a better drug for increasing brain ACh for the therapy of patients with SDAT than THA. amiridin, HP-029 and physostigmine because of its higher selectivity to the CNS.

Acknowledgments: We are very grateful to Drs. $S$. Kogiso and A. Yoshitake, Biochemistry and Toxicology Laboratory, Sumitomo Chemical Co., Ltd., for kindly providing us with information on the Ames test.

\section{References}

1 Davies, P. and Maloney, A.J.F.: Selective loss of central cholinergic neurons in Alzheimer's disease. Lancet 2, 1403 (1976)

2 Bowen, D.M., Smith, C.B., White, P. and Dawson, A.N.: Neurotransmitter-related enzymes and indices of hypoxia in senile dementia and other abiotrophies. Brain 99, 459-496 (1976)

3 Perry, E.K., Perry, R.H., Blessed, G. and Tomlinson, B.E.: Necropsy evidence of central cholinergic deficits in senile dementia. Lancet 1, 189 (1977)

4 White, P., Hiley, C.R., Goodhardt, M.J., Carrasco, L.H., Keet, J.P. and Williams, I.E.I.: Neocortical cholinergic neurons in elderly people. Lancet 1, 668-671 (1977)

5 Op Den Velde, W. and Stam, F.C.: Some cerebral proteins and enzyme systems in Alzheimer's presenile and senile dementia. J. Am. Geriatr. Soc. 24, 12-16 (1976)

6 Drachman, D.A. and Lavitt, J.: Human memory and the cholinergic system. A relationship to aging? Arch. Neurol. 30, 113-121 (1974)

7 Drachman, D.A.: Memory and cognitive function in man: does the cholinergic system have a specific role? Neurology 27, 783-790 (1977)

8 Perry, E.K., Tomlinson, B.E., Blessed, G., Bergman, K., Gilson, P.H. and Perry, R.H.: Correlation of cholinergic abnormalities with senile plaques and mental test scores in senile dementia. Br. Med. J. 2, 1457-1459 (1978)

9 Thal, L.T., Fuld, P.A., Mathur, D.M. and Sharpless, N.S.: Oral physostigmine and lecithin improve memory in Alzheimer's disease. Ann. Neurol. 13, 491-496 (1983)

10 Stern, Y., Sano, M. and Mayeux, R.: Long-term administration of oral physostigmine in Alzheimer's disease. Neurology 38, 1837-1841 (1988)

11 Summers, W.K., Majorski, L.V., Marsh, G.M., Tachiki, K. and Kling, A.: Oral tetrahydroaminoacridine in long-term treatment of senile-dementia, Alzheimer type. N. Engl. J. Med. 315, 1241 (1986)

12 Kaul, P.N.: Enzyme inhibiting action of tetrahydroaminoacridine and its structural fragments. J. Pharm. Pharmacol. 14, 243-248 (1962)

13 Rosic, N. and Milosevic, M.P.: The effect of tetrahydroaminoacridine on cholinesterase activity in brain of the rat. lugoslav. Physiol. Pharmacol. Acta 3, 43-47 (1967)

14 Townsend, S.E. and Sehgel, N.S.: Mutagenicity evaluation of tetrahydro-aminoacridine by the Salmonella/microsome mutagenicity Ames test. Drug Dev. Res. 14, 91-94 (1988)

15 Kuribara, H.: Effects of amiridin on ambulatory activity and discrete shuttle avoidance response in mice. Folia Pharmacol. Japon. 88, 299-307 (1986) (Abs. in English)

16 Nabeshima, T., Yoshida, S. and Kameyama, T.: Effects of the novel compound NIK-247 on impairment of passive avoidance response in mice. Eur. J. Pharmacol. 154, 263-269 (1988) 
17 Shutske, G.M., Pierrat, F.A., Cornfeldt, M.L., Szewczak, M.R., Huger, F.P. and Bores, G.M.: ( \pm ) -9-Amino-1,2,3,4 - tetrahydroacridine-1-ol. A potential Alzheimer's disease therapeutic of low toxicity. J. Med. Chem. 31, 1278-1279 (1988)

18 Tanaka, Y., Sakurai, M. and Hayashi, S.: Effect of scopolamine and HP.-029, a cholinesterase inhibitor. on long-term potentiation in hippocampal slices of the guinea pig. Neurosci. Lett. 98, 179183 (1989)

19 Schoemaker, H. and Nickolson, V.J.: Dopamine uptake by rat striatal synaptosomes: time and temperature dependent decay and protection by dithiothreitol and dopamine. J. Neurochem. 40, 922-928 (1983)

20 Ellman, G.L., Courtney, D., Andres, V. and Featherstone, R.M.: A new and rapid colorimetric determination of acetylcholinesterase activity Biochem. Pharmacol. 7, 88-95 (1961)

21 Palacios, J.M., Bollinger, G., Closse, A., Enz, A., Gmelin, G. and Malanowski, J.: The pharmacological assessment of RS-86 (2-ethyl-2,8-diazaspiro-[4,5]-decan-1,3-dion hydrobromide). A potent, specific muscarinic acetylcholine receptor agonist. Eur. J. Pharmacol. 125, 45-62 (1986)
22 Rathbun, R.C. and Slater, L.H.: Amitriptyline and nortriptyline as antagonists of central and peripheral cholinergic activation. Psychopharmacologia (Berlin) 4, 114-125 (1963)

23 Ikarashi, Y., Sasahara, T, and Maruyama, Y.: A simple method for determination of choline (Ch) and acetylcholine (ACh) in rat brain regions using high-performance liquid chromatography with electrochemical detection (HPLC-ECD). Folia Pharmacol. Japon. 84, 529-536 (1984) (Abs. in English)

24 Ajima, A. and Kato, T.: Brain dialysis: detection of acetylcholine in the striatum of unrestrained and unanesthetized rats. Neurosci. Lett. 81, 129-132 (1987)

25 Peacocke, A.R. and Skerrett, J.N.H.: The interaction of aminoacridines with nucleic acids. Trans. Faraday Soc. 52, 261-279 (1956)

26 Heilbronn, E.: Inhibition of cholinesterases by tetrahydroaminacrin. Acta Chem. Scand. 15, 1386-1390 (1961)

27 Spencer, P.S.J.: Activity of centrally acting and other drugs against tremor and hypothermia induced in mice by tremorine. Br. J. Pharmacol. $25,442-455$ (1965) 